\title{
Perfluorocarbons Prevent Lung Injury and Promote Development during Artificial Placenta Support in Extremely Premature Lambs
}

\author{
Joseph T. Church Elena M. Perkins Megan A. Coughlin Jennifer S. McLeod \\ Katherine Boss J. Kelley Bentley Marc B. Hershenson Raja Rabah \\ Robert H. Bartlett George B. Mychaliska \\ Department of Surgery, University of Michigan Medical School, Ann Arbor, MI, USA
}

\section{Keywords \\ Artificial placenta - Extracorporeal life support . \\ Extracorporeal membrane oxygenation - Extreme \\ prematurity $\cdot$ Perfluorocarbon $\cdot$ Lung development}

\begin{abstract}
Background: Extremely premature neonates suffer high morbidity and mortality. An artificial placenta (AP) using extracorporeal life support (ECLS) is a promising therapy. $\mathbf{O b}$ jectives: We hypothesized that intratracheal perfluorocarbon (PFC) instillation during AP support would reduce lung injury and promote lung development relative to intratracheal amniotic fluid or crystalloid. Methods: Lambs at an estimated gestational age (EGA) 116-121 days (term 145 days) were placed on venovenous ECLS with jugular drainage and umbilical vein reinfusion and intubated. Airways were managed by the instillation of amniotic fluid and tracheal occlusion (TO; $n=4)$, or lactated Ringer's (LR; $n=4)$ or perfluorodecalin (a PFC) without occlusion $(n=4)$. After 7 days, the animals were sacrificed. Early (EGA 116-121 days) and late (EGA 125-131 days) tissue control lambs were delivered and sacrificed. Lungs were formalin-inflated to $30 \mathrm{~cm} \mathrm{H}_{2} \mathrm{O}$ and sectioned for histology. Injury was scored by an unbiased
\end{abstract}

(c) 2018 S. Karger AG, Basel

E-Mail karger@karger.com www.karger.com/neo pathologist. Slides were immunostained for PDGFR- $a$ and a-actin; development was quantified by the area fraction of double-positive tips. Surfactant protein-C (SP-C) concentration in bronchoalveolar lavage fluid was quantified using ELISA. Results: Total injury scores were lower in PFC lungs $(1.8 \pm 1.7)$ than in TO $(6.5 \pm 2.1 ; p=0.01)$ and LR lungs $(5.5 \pm$ $2.4 ; p=0.01)$. The area fraction of double-positive alveolar tips appeared higher in PFC lungs than in TO lungs (0.18 \pm 0.007 vs. $0.008 \pm 0.004 ; p=0.07$ ). SP-C concentration was higher in PFC lungs than in TO lungs ( $37.9 \pm 7.6$ vs. $20.0 \pm 5.4$ $\mathrm{pg} / \mathrm{mL} ; p=0.005)$, and both early $(12.4 \pm 1.7 \mathrm{~g} / \mathrm{mL} ; p=0.007)$ and late tissue control lungs ( $15.1 \pm 5.0 \mathrm{pg} / \mathrm{mL} ; p=0.0008)$. Conclusion: During AP support, intratracheal PFC prevents lung injury and promotes normal lung development better than crystalloid or amniotic fluid with TO.

(c) 2018 S. Karger AG, Basel

\section{Introduction}

Premature neonates born at $\leq 28$ weeks estimated gestational age (EGA) suffer high morbidity and mortality, with survival of $<50 \%$ at $<24$ weeks [1]. The immaturity of multiple organ systems contributes to this morbidity, 


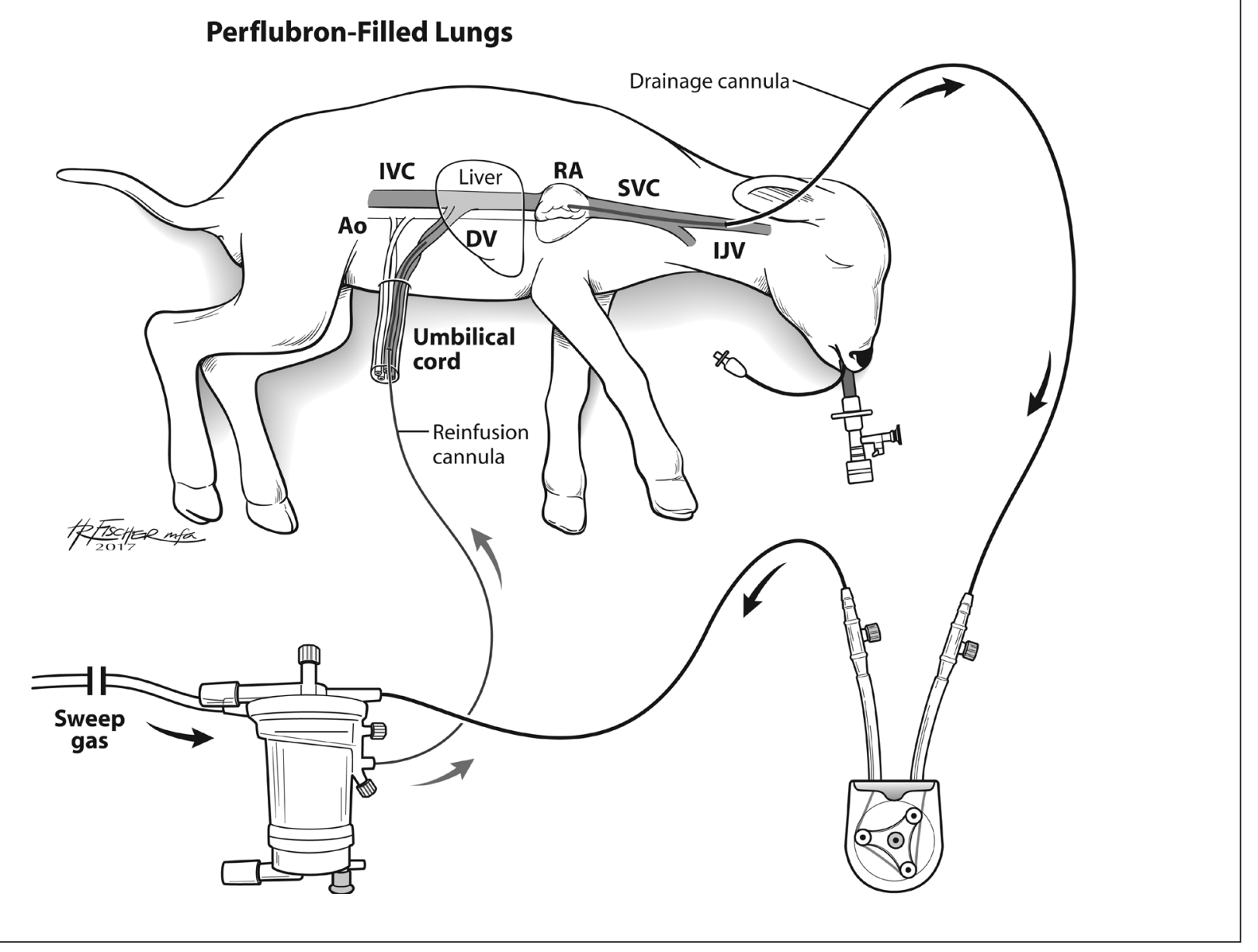

Fig. 1. Schematic of the artificial placenta. Blood is drained from the right jugular vein by a collapsible-tubing roller pump (Mpump; MC3, Ann Arbor, MI, USA) and propelled to an oxygenator/heat exchanger (Medos HiLite, Xenios, Heilbronn, Germany), then returned via an umbilical vein. The second umbilical vein is accessed for IV fluid and medication administration, and an um-

mostly notably the lungs [2-5]. Though potentially lifesaving, mechanical ventilation, the current standard of care for respiratory support of these premature newborns, is often inadequate for survival and may even be harmful, leading to pulmonary injury and arrested lung development [6-8].

A solution to this problem would be an artificial placenta (AP) consisting of 4 components: (1) extracorporeal life support (ECLS), (2) fluid-filled lungs, (3) avoidance of mechanical ventilation, and (4) the preservation of fetal circulation. Given that pulmonary morbidity decreases with increasing gestational age [2], the goal of the $\mathrm{AP}$ is to allow premature lungs to develop to the point bilical arterial line is placed for hemodynamic monitoring and blood gas sampling. The lamb is intubated and the lungs remain filled with either amniotic fluid, lactated Ringer's, or perfluorodecalin. Ao, aorta; DV, ductus venosus; IJV, internal jugular vein; IVC, inferior vena cava; RA, right atrium; SVC, superior vena cava.

where they can provide adequate gas exchange to support the neonate. We have previously demonstrated that the AP can support otherwise moribund premature lambs for $>7$ days [9], and that lung development continues during this support $[10,11]$.

During these early experiments, lambs were intubated and the endotracheal tube (ETT) filled with amniotic fluid, and then clamped to emulate tracheal occlusion (TO), which has been shown to induce lung growth and development prenatally in fetuses with congenital diaphragmatic hernia $(\mathrm{CDH})[12,13]$. We questioned whether alternative methods of airway management would cause less lung injury and promote development. Specifically, 
perfluorocarbons (PFCs) have been shown to encourage lung development, decrease injury, and increase surfactant production [14-18]. We hypothesized that intratracheally instilled PFC would result in greater lung development and less injury than alternative methods, including TO, during support with an AP.

\section{Methods}

The sheep in this experiment were treated in compliance with the Guide for the Care and Use of Laboratory Animals (US NIH). The methods were approved by the University of Michigan Institutional Animal Care and Use Committee (protocol No. 00007211).

\section{AP Support}

Premature lambs of EGA $118 \pm 3$ days were delivered via laparotomy and hysterotomy. This EGA was selected because lung development at this stage is analogous to that of a 24-week human fetus [9]. Cannulas (10-14 french; Terumo, Ann Arbor, MI, USA) were placed in the right jugular (drainage) and umbilical (reinfusion) veins, and the circuit was completed using $1 / 4$ tubing (Tygon: Lima, OH, USA), a roller pump (M-pump; MC3, Ann Arbor, MI, USA), and oxygenator/heat exchanger (either Capiox Baby Rx, Terumo, or Medos HiLite, Xenios, Heilbronn, Germany; Fig. 1). Venovenous (VV) ECLS was initiated. A 5-french triple-lumen venous line was placed in the second umbilical vein for administering IV fluids and medications, and a 5-french umbilical arterial line (both lines from Covidien-Medtronic; Minneapolis, MN, USA) was placed in the umbilical artery for hemodynamic monitoring and arterial blood gas (ABG) sampling.

The lambs were intubated. The airway was then managed by 1 of 3 strategies: instilling a PFC, i.e., 100\% perfluorodecalin (Origen; Austin, TX, USA) into the ETT $(n=4)$, instilling lactated Ringer's (LR) into the ETT as a neutral crystalloid solution $(n=4)$, or instilling amniotic fluid followed by ETT clamping, i.e., TO $(n=4)$. In the PFC and LR groups, the ETT was attached to a pressure-transducing line which allowed for breathing movements and the measurement of airway pressure (maintained at $4-8 \mathrm{~mm} \mathrm{Hg}$ ), but did not allow for gas exchange. In the TO group, clamping of the ETT resulted in static fluid within the airways (the ETT was not opened to prevent depressurization and/or the introduction of air). ECLS was managed according to goal ABG parameters: $\mathrm{pH}$ 7.30-7.45, $\mathrm{pCO}_{2} 35-50 \mathrm{~mm} \mathrm{Hg}, \mathrm{pO}_{2} 25-35 \mathrm{~mm} \mathrm{Hg}$, and $\mathrm{SpO}_{2}$ $60-75 \%$. Echocardiography was performed $3 \mathrm{~h}$ after the initiation of AP support, to confirm ductal patency. AP support was continued for the proposed 7 days in all groups. The lambs were given total parenteral nutrition, empiric piperacillin-tazobactam (100 $\mathrm{mg} / \mathrm{kg})$, and solumedrol $(0.63 \mathrm{mg} / \mathrm{kg})$ at regular intervals. They were also anticoagulated with IV heparin titrated to an activated clotting time of 200-250 s, and given prostaglandin $E_{1}(0.02 \mu \mathrm{g} / \mathrm{kg} /$ $\mathrm{min}$ ) to maintain ductus arteriosus patency.

\section{Tissue Control Lambs}

Early (118 \pm 3 days EGA; $n=5)$ and late (128 \pm 3 days; $n=5)$ tissue control lambs were delivered in the same way as AP lambs. They were immediately sacrificed for bronchoalveolar lavage (BAL) and tissue procurement.

PFCs and the Artificial Placenta
Table 1. Hemodynamic and umbilical blood gas values

\begin{tabular}{lccc}
\hline & PFC & TO & LR \\
\hline Hemodynamic values & & & \\
Heart rate, beats/min & $210 \pm 10$ & $209 \pm 10$ & $215 \pm 13$ \\
MAP, mm Hg & $50.4 \pm 4.1$ & $42.8 \pm 4.8$ & $47 \pm 4.4$ \\
Circuit flow, mL/min/kg & $118 \pm 12$ & $121 \pm 24$ & $109 \pm 5$ \\
\hline Arterial blood gas values & & & \\
pH & $7.35 \pm 0.01$ & $7.31 \pm 0.10$ & $7.36 \pm 0.03$ \\
pCO $_{2}, \mathrm{~mm} \mathrm{Hg}$ & $47.9 \pm 5.3$ & $47.0 \pm 5.3$ & $44.4 \pm 7.4$ \\
$\mathrm{pO}_{2}, \mathrm{~mm} \mathrm{Hg}$ & $28.4 \pm 2.4$ & $38.9 \pm 8.6$ & $30.6 \pm 2.8$ \\
$\mathrm{SaO}_{2}, \%$ & $63.0 \pm 2.5$ & $73.2 \pm 5.7$ & $69.0 \pm 5.2$ \\
$\mathrm{Lactate} \mathrm{mmol} / \mathrm{dL}$ & $2.6 \pm 1.0$ & $3.6 \pm 1.1$ & $3.1 \pm 1.6$ \\
\hline Venous blood gas values & & & \\
$\mathrm{pCO}_{2}, \mathrm{~mm} \mathrm{Hg}$ & $50.6 \pm 5.8$ & $51.1 \pm 3.1$ & $49.0 \pm 9.3$ \\
$\mathrm{pO}_{2}, \mathrm{~mm} \mathrm{Hg}$ & $23.4 \pm 2.0$ & $29.7 \pm 6.9$ & $24.9 \pm 1.5$ \\
$\mathrm{SaO}_{2}, \%$ & $50.5 \pm 5.6$ & $59.4 \pm 2.8$ & $56.0 \pm 3.2$ \\
\hline
\end{tabular}

Values are expressed as means \pm SD. PFC, perfluorocarbon; TO, tracheal occlusion; LR, lactated Ringer's; MAP, mean arterial pressure.

\section{Necropsy and Lung Preparation}

Following sacrifice, lungs were procured. BAL of the right lower lobe was performed with $10 \mathrm{~mL}$ normal saline, followed by the aspiration of $4 \mathrm{~mL}$ of BAL fluid (BALF). BALF was centrifuged at 3,600 rpm for $15 \mathrm{~min}$, and the supernatant was extracted for analysis. The left atrium was incised, and the pulmonary vasculature flushed with PBS plus EDTA via the pulmonary artery, followed by $10 \%$ formalin. The airways were inflated with $10 \%$ formalin via the trachea to a pressure of $30 \mathrm{~cm} \mathrm{H}_{2} \mathrm{O}$. The distal $2 \mathrm{~cm}$ of the left lower lobe was excised and sent for tissue processing. Transverse sections $(5 \mu \mathrm{m})$ were cut from the left lower lobe for histopathologic evaluation and immunostaining.

\section{Histopathology and Lung Injury}

Slides were stained with hematoxylin and eosin (H\&E) and evaluated by a single pathologist, in a blinded fashion, who assigned each an injury severity score [19]. Variables scored were alveolar and interstitial inflammation, alveolar and interstitial hemorrhage, edema, atelectasis, and necrosis. Each variable was scored on a scale of $0-4$; no injury scored 0 , and a point was added for every $25 \%$ of the field identified as injured, up to a score of 4 $(100 \%)$.

\section{Alveolar Development}

Transition from the saccular to the alveolar stage of lung development in sheep begins at around 120 days of gestation [20,21]. Accordingly, we assessed lung development by measuring the presence of platelet-derived growth factor receptor- $\alpha$ (PDGFR- $\alpha$ ) and $\alpha$-smooth muscle actin double-positive myofibroblasts, which serve as markers of alveolar development [22]. Lung sections were labeled with antibodies for PDGFR- $\alpha$ (Santa Cruz Biotechnology, Santa Cruz, CA, USA) and anti- $\alpha$-smooth muscle actin (Cy 3 conjugate, Sigma-Aldrich, St Louis, MO, USA). The anti-PDGFR- $a$ 

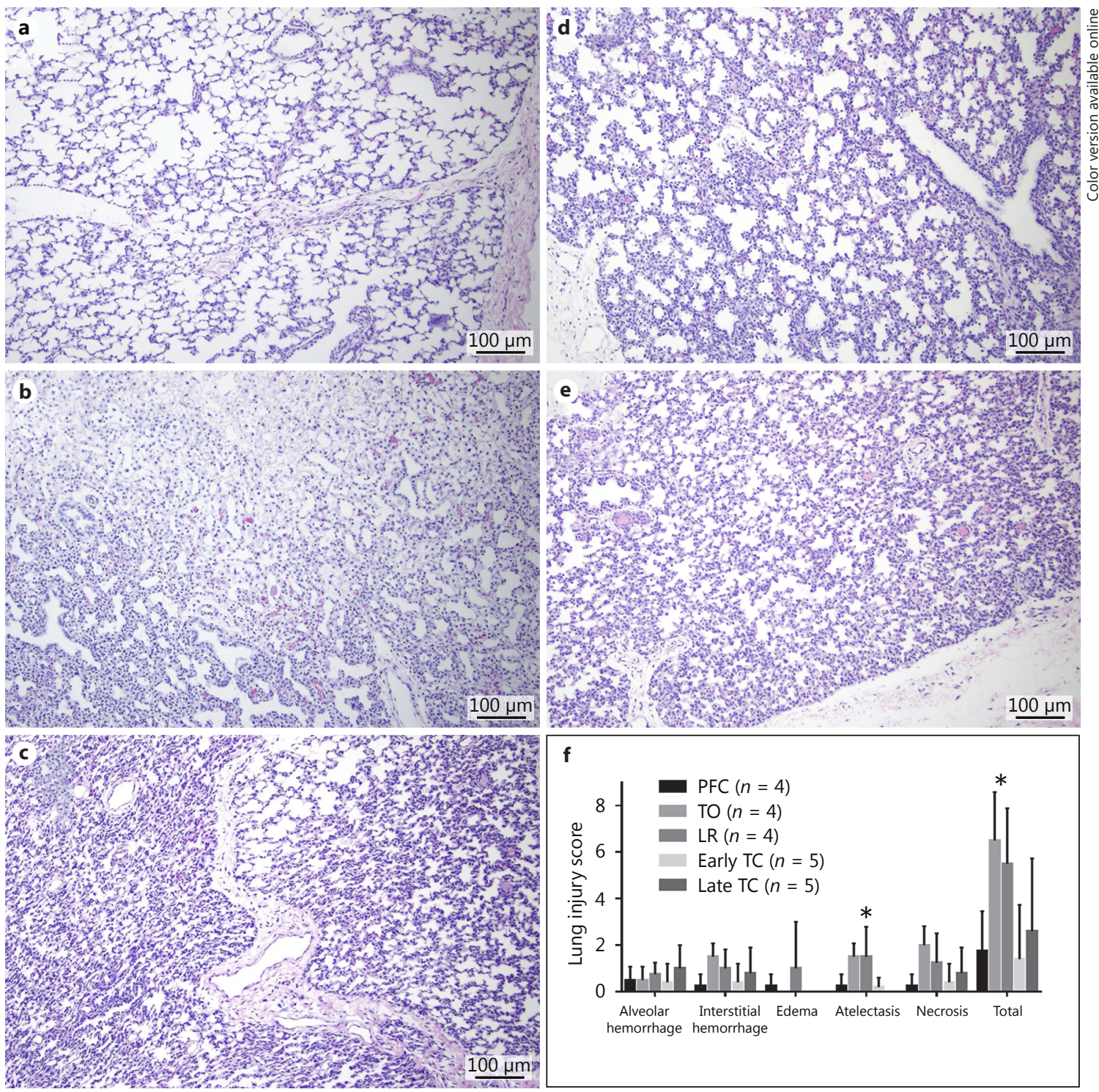

Fig. 2. Assessment of lung injury. Representative slides at magnification from the left lower lobe of lungs from artificial placentasupported lambs with lungs managed by: PFC (a), TO (b), LR (c), early TC (d), and late TC (e). H\&E. $\times 10$. PFC instillation resulted in better and more uniform inflation than in TO or LR lungs, similar to TC lambs of both gestational ages. $\mathbf{f}$ Lung slides were scored $0-4$ for injury by a pathologist blinded to the experimental group

was conjugated to AlexaFluor $488 \mathrm{~N}$-hydroxy succinimidyl ester (Fisher Scientific, Hampton, NH, USA). Nuclei were visualized with Hoechst 33342 (Sigma-Aldrich). The tips of alveolar secondary crests were identified by the colocalization of PDGFR- $\alpha$ and $a$-actin [22]. An $18 \times 13$ point grid was laid over lung micrograph images using the public domain NIH Image program (http://rsb. info.nih.gov/nih-image). Alveolarization was quantified by calculating the ratio of points falling on double-positive alveolar tips to the total number of reference points (area fraction), with a larger in multiple categories, then summed for total injury scores. Significant differences in atelectasis were seen in lungs from PFC and TO lambs. PFC lungs had lower total injury scores than both TO and LR lambs. Mean \pm SD. ${ }^{*} p<0.05$ (ANOVA). TO, tracheal occlusion; LR, lactated Ringer's; TC, tissue control; PFC, perfluorocarbon.

area fraction signifying more advanced lung development. For each sample, five fields at $\times 40$ magnification were used to calculate the area fraction, and these values were averaged.

\section{Type II Pneumocyte Density and Surfactant Protein-C}

\section{Production}

Using immunohistochemistry, lung sections were labeled with polyclonal rabbit anti-prosurfactant protein C (anti-SP-C; Millipore \#AB3786) with the development of color by using a Vecta- 
stain rabbit IgG ABC kit (Vector Labs \#PK-4001). Alveolar cells that stained positive for SP-C were identified as type II pneumocytes. The fraction of alveolar cells comprising type II pneumocytes was calculated and served as a marker of development. Fractions were calculated for 5 randomly selected images of lung tissue at $\times 40$ for each sample, and these values were averaged.

ELISA was used to quantify concentrations of SP-C in BALF samples, as SP-C is a key component in the surfactant's ability to decrease surface tension [23]. As BALF collection was adopted as part of our experimental protocol only later in the experiment, 2 lambs did not undergo BAL at necropsy ( $n=3$ for PFC and TO).

\section{Statistical Analysis}

Statistical analysis was performed using GraphPad Prism (GraphPad, La Jolla, CA, USA) and SPSS v22.0 (IBM Corp., Armonk, NY, USA). Comparisons were made using ANOVA. A $p$ value $<0.05$ was considered significant.

\section{Results}

\section{Physiology of AP Support}

Mean hemodynamic parameters and umbilical blood gas values are displayed in Table 1 . Heart rate and mean arterial pressure were within physiologic ranges for gestational age and ABG values fell within or near goal ranges. Echocardiography $3 \mathrm{~h}$ after initiating AP support revealed a patent ductus arteriosus in all lambs, including those who had received an initial PFC bolus. Echocardiography beyond day 1 of support was not possible in the PFC lambs as views were obscured by the distribution of PFC throughout the airways.

\section{Lung Injury}

Representative lung histology is pictured in Figure 2a-e. Qualitatively, PFC lungs appeared more uniformly inflated than TO and LR lungs. Lung histopathology from each lamb was scored by a pathologist in a blinded fashion. No alveolar or interstitial inflammation was observed in any sample from any group. Total injury differed between groups, with PFC lungs $(1.8 \pm 1.7)$ demonstrating lower injury than TO $(6.5 \pm 2.1 ; p=0.01)$ and LR lungs $(5.5 \pm 2.4 ; p=0.01$; Fig. 2 f); total injury was similar to that in both early and late tissue controls $(1.4 \pm 2.6$ and $2.6 \pm$ 3.1 , respectively). Differences between groups appeared most pronounced in atelectasis $(p=0.004)$, with PFC lungs again resembling tissue control lungs, i.e., with lower atelectasis scores than either TO or LR.

\section{Alveolar Development}

Representative immunostained slides are displayed in Figure 3a-e. Red represents $\alpha$-actin and green represents
PDGFR- $\alpha$; co-localization of both signals at the tips of alveolar secondary crests signify double-positive tips. Lungs in all 5 groups displayed these double-positive tips, but they were more evident in the PFC and LR lungs than in the TO lungs. LR lungs also displayed $\alpha$-actin accumulation in the alveolar interstitium, a phenomenon not seen in PFC or TO lungs. The area fraction of doublepositive alveolar tips differed between groups $(p=0.03)$, with much of this driven by the difference in area fraction between PFC lungs $(0.018 \pm 0.007)$, TO lungs $(0.008 \pm$ $0.004 ; p=0.07)$, and early tissue control lungs (0.009 \pm $0.002 ; p=0.09)$. Area fractions between PFC, LR, and late tissue control lungs appeared similar (Fig. 3f).

\section{Type II Pneumocyte Density and SP-C Production}

Representative immunohistochemistry is displayed in Figure $4 \mathrm{a}-\mathrm{e}$, where type II pneumocytes are stained brown. PFC lungs demonstrated higher type II pneumocyte fractions $(0.76 \pm 0.10)$ than either TO $(0.37 \pm 0.17 ; p$ $=0.007)$ or LR $(0.40 \pm 0.10 ; p=0.003)$ lungs and early $(0.32 \pm 0.09 ; p=0.002) /$ late $(0.30 \pm 0.14 ; p=0.001)$ tissue controls (Fig. 4f). BALF samples were also analyzed for SP-C concentration, using ELISA to assess surfactant production (Fig. 4g). PFC lungs exhibited higher SP-C concentrations than TO lungs $(37.9 \pm 7.6$ vs. $20.0 \pm 5.4$ $\mathrm{pg} / \mathrm{mL} ; p=0.005)$ and early $(12.4 \pm 1.7 \mathrm{pg} / \mathrm{mL} ; p=0.007) /$ late $(15.1 \pm 5.0 \mathrm{pg} / \mathrm{mL} ; p=0.0008)$ tissue control lungs.

\section{Discussion}

An AP utilizing ECLS for gas exchange while maintaining fluid-filled lungs and fetal circulation could potentially decrease the high morbidity and mortality faced by extremely premature newborns. We have previously reported 10-day support of otherwise moribund extremely premature lambs with a transition to mechanical ventilatory support and ongoing lung development [10]. The goal of this study was to identify the optimal airway management strategy to promote lung development and avoid injury during support.

We found that intratracheal PFC reduced lung injury relative to $\mathrm{TO}$ or intratracheal crystalloid, most notably in reducing atelectasis. PFC also appeared to promote development relative to $\mathrm{TO}$, manifested primarily in a significantly higher concentration of type II pneumocytes as well as in a trend toward greater alveolarization, as seen with higher area fractions of double-positive alveolar secondary crests. LR resulted in $\alpha$-actin accumulation in the alveolar interstitium, a phenomenon associated with in- 

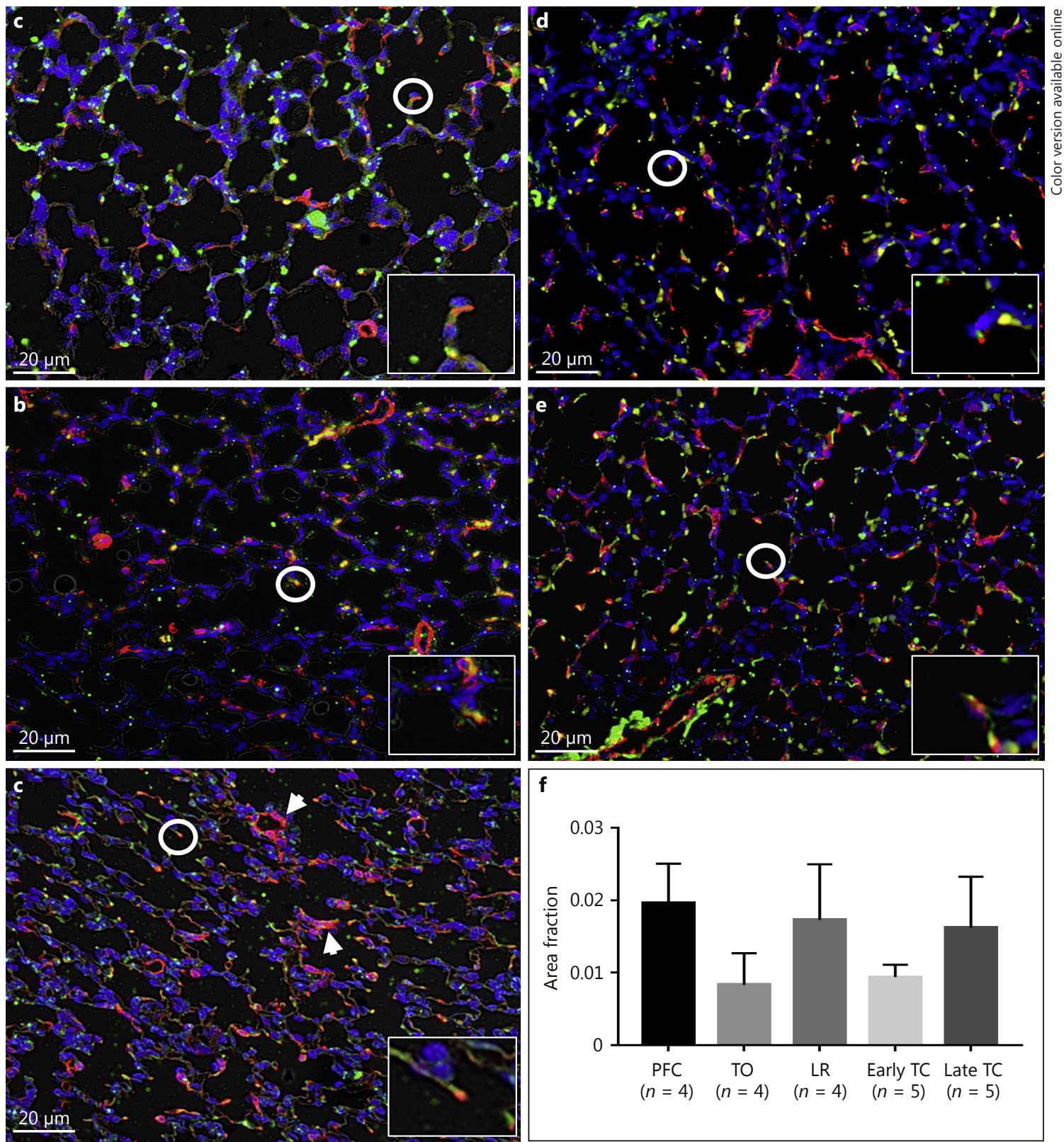

Fig. 3. Assessment of lung development. Images following immunofluorescence staining for PDGFR- $\alpha$ (green) and $\alpha$-actin (red). $\times 20$. Colocalization of signals at the tips of alveolar crests represent double-positive tips (white circles), signifying active lung development and maturation. Insets Double-positive tips are enlarged to show detail. a PFC lungs. b TO lungs. c LR lungs. d Early TC lungs. e Late TC lungs. All groups displayed double-positive tips; however, these were qualitatively more evident in PFC lungs than in LR or TO lungs. LR lungs also displayed $\alpha$-actin accumulation in the alveolar interstitium (white arrows), a phenomenon not seen in PFC or TO lungs. $\mathbf{f}$ The ratio of double-positive tips falling on standardized grid points/total grid points represents the area fraction. The area fraction of double-positive tips differed between groups ( $p=0.03$, ANOVA), with fractions in PFC lungs appearing higher than in TO and early TC lungs, and similar to that in LR and late TC lungs. Mean \pm SD. TO, tracheal occlusion; LR, lactated Ringer's; TC, tissue control; PFC, perfluorocarbon. 


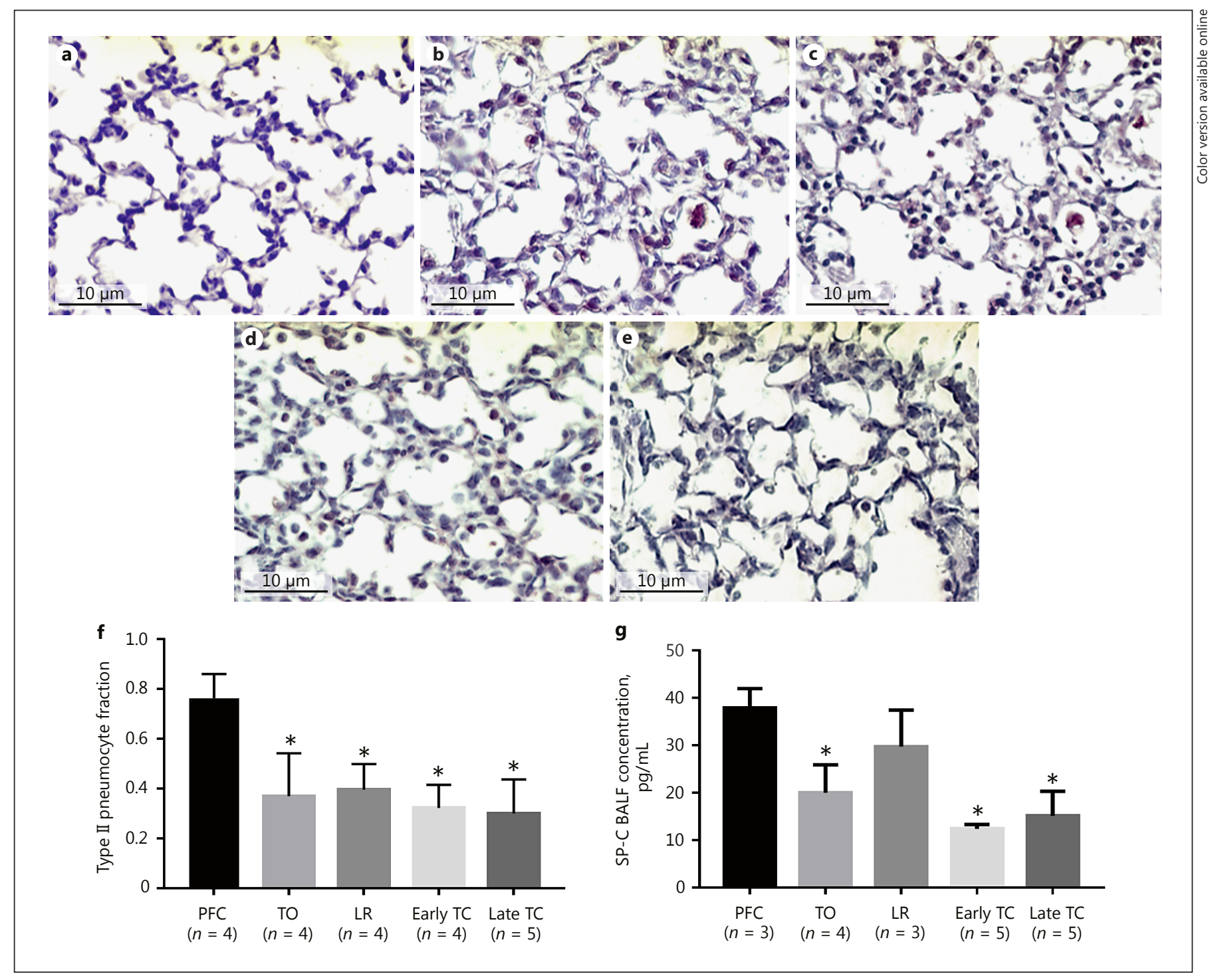

Fig. 4. Type II pneumocyte density and SP-C expression. Images at $\times 40$ magnification after surfactant protein $\mathrm{C}(\mathrm{SP}-\mathrm{C})$ immunohistochemistry. a PFC lungs. b TO lungs. c LR lungs. d Early TC lungs. e Late TC lungs. Alveolar cells that stained positive for SP-C (brown) are identified as type II pneumocytes. $\mathbf{f}$ The fraction of alveolar cells comprising type II pneumocytes was calculated, with PFC-filled lungs exhibiting significantly higher type II pneumocyte fractions than any other airway management strategy or early or late TC. At necropsy, prior to lung sectioning, bronchoalveolar lavage with $10 \mathrm{ml}$ of normal saline was performed in the right low-

jury usually associated with high-pressure ventilation; this was not seen in PFC lungs. Furthermore, PFC greatly enhanced SP-C secretion relative to tissue controls, likely driven by the higher density of type II pneumocytes. The use of PFC was thus found to be the optimal airway management strategy during AP support.

PFCs and the Artificial Placenta er lobe. Samples were centrifuged to remove debris, and the supernatant was analyzed for SP-C concentration using ELISA. SP-C concentrations were higher in PFC lungs than in TO lungs, and were also higher than concentrations in early or late TC lungs. g SP-C concentrations were similar in PFC and LR lungs. Mean \pm $\mathrm{SD}{ }^{*} p<0.01$ compared to PFC (ANOVA; the Hochberg test for individual comparisons). TO, tracheal occlusion; LR, lactated Ringer's; TC, tissue control; PFC, perfluorocarbon; BALF, bronchoalveolar lavage fluid.

Pulmonary morbidity is the hallmark of many neonatal diseases, including prematurity, respiratory distress syndrome, and $\mathrm{CDH}$. CDH has been the subject of significant research investigating strategies that accelerate lung development in utero, that we felt could also potentially be employed to promote lung development during

Neonatology 2018;113:313-321 
AP support. The most studied of these is fetal TO. Taking advantage of the secretory nature of the fetal lungs, TO has been found to reverse the hypoplastic effects of $\mathrm{CDH}$ in animal and human fetuses [13, 24]. However, TO has also been found to decrease type II pneumocyte density and surfactant production $[25,26]$. In our early experimentation with the AP, the benefit of TO was limited, as it did not promote lung development as we had expected, and actually appeared to cause injury and suppress surfactant production. LR was selected in our experiments as an alternative to amniotic fluid to allow for breathing movements and airway pressure transduction, and because its electrolyte composition is comparable to that of amniotic fluid [27]. While this seemed to improve lung maturation, we still observed greater-than-expected lung injury. Furthermore, LR appeared to be absorbed into the circulation via the airways over time, necessitating the addition of fluid to the airways, and a wider variation in airway pressure, systemic fluid, and electrolyte shifts.

PFCs have also been shown to promote lung development. They are inert, nontoxic, high-density, low-viscosity liquids that are excellent carriers of both oxygen and $\mathrm{CO}_{2}$ [28]. This gas-carrying capacity led to PFC use in liquid ventilation in both adult and pediatric trials [29, 30]. More importantly, the high density of PFCs and their ability to increase pulmonary compliance allows for PFCinduced lung growth, which has been seen both in animal models and in infants with $\mathrm{CDH}[14,15,28,30]$. Unlike TO, PFCs have been shown to increase surfactant production in animal models [17] and decrease inflammation and oxidative injury when used intratracheally $[16,18]$.

These effects of PFCs are highly desirable during AP support. Our system did not utilize liquid ventilation, as our goal was to minimize alveolar oxygen tension, to avoid pulmonary vasodilation and the reversal of fetal circulation. The effects of PFCs on gas exchange were minimal, as shown by the preservation of the fetal circulation and the stability of low oxygen tension at a stable circuit flow. However, the effects of PFCs on lung development and injury in our ovine model were notable. Of particular interest was the increased surfactant production; this was limited with TO. Since surfactant deficiency is associated with respiratory distress syndrome, a common complication of prematurity, we would expect that maximizing surfactant production would optimize the chances of successfully weaning a premature infant from AP support to breathing.

Our study was limited by a lack of lung functional assessment following AP support. However, we have previously reported that, after 10 days of AP support, lambs could be transitioned to mechanical ventilation with lung mechanics similar to gestational age-matched controls [10]. These experiments were primarily performed using TO or LR airway management strategies, so we expect that PFC-filled lungs will transition to ventilation with even greater success. Additionally, the complexity of our model represents a limitation. By nature, these lambs have multiple problems; to address these problems, certain aspects of care must be adjusted. However, as our experience in caring for these animals has grown, we have standardized IV nutrition, nearly eliminated the need for vasopressors, and discontinued persistent sedation in order to allow the animals to breathe PFCs and move spontaneously. Future directions will include utilizing the AP to rescue premature lambs from failed mechanical ventilation, standardizing the process of weaning from AP support, and optimizing critical care following weaning, to allow for long-term survival.

\section{Conclusion}

Instillation of PFCs intratracheally during AP support minimizes lung injury and maximizes lung development. We therefore propose that the use of PFCs represents the ideal airway management strategy during support with the AP.

\section{Disclosure Statement}

The authors declare no conflicts of interest.

\section{Funding Source}

The research presented in this paper was funded by the $\mathrm{Na}$ tional Institutes of Health 1R01HD073475-01A1.

\section{References}

1 Blencowe $\mathrm{H}$, Cousens S, Oestergaard MZ, Chou D, Moller AB, Narwal R, Adler A, Vera Garcia C, Rohde S, Say L, Lawn JE: National, regional, and worldwide estimates of preterm birth rates in the year 2010 with time trends since 1990 for selected countries: a systematic analysis and implications. Lancet 2012;379: 2162-2172.

2 Stoll BJ, Hansen NI, Bell EF, Shankaran S, Laptook AR, Walsh MC, et al: Neonatal outcomes of extremely preterm infants from the NICHD Neonatal Research Network. Pediatrics 2010;126:443-456. 
3 Stoll BJ, Hansen NI, Bell EF, Walsh MC, Carlo WA, Shankaran S, et al: Trends in care practices, morbidity, and mortality of extremely preterm neonates, 1993-2012. JAMA 2015;314:1039-1051.

4 Laughon M, O'Shea MT, Allred EN, Bose C, Kuban K, Van Marter LJ, Ehrenkranz RA, Leviton A: Chronic lung disease and developmental delay at 2 years of age in children born before 28 weeks' gestation. Pediatrics 2009; 124:637-648.

5 Manktelow BN, Seaton SE, Field DJ, Draper ES: Population-based estimates of in-unit survival for very preterm infants. Pediatrics 2013;131:e425-e432.

6 Chambers HM, van Velzen D: Ventilator-related pathology in the extremely immature lung. Pathology 1989;21:79-83.

7 Attar MA, Donn SM: Mechanisms of ventilator-induced lung injury in premature infants. Semin Neonatol 2002;7:353-360.

8 Philip AG: Bronchopulmonary dysplasia: then and now. Neonatology 2012;102:1-8.

9 Bryner B, Gray B, Perkins E, Davis R, Hoffman H, Barks J, Owens G, Bocks M, RojasPena A, Hirschl R, Bartlett R, Mychaliska G: An extracorporeal artificial placenta supports extremely premature lambs for 1 week. J Pediatr Surg 2015;50:44-49.

10 Church JT, Coughlin MA, Perkins EM, Hoffman HR, Bartlett RH, Mychaliska GB: The artificial placenta: does lung development continue during extracorporeal support? AAP Meeting, San Francisco, 2016.

11 Coughlin MA, Werner NL, Church JT, Perkins EM, Rabah R, Bartlett RH, Mychaliska GB: The artificial placenta avoids damage caused by mechanical ventilation. ASAIO 62nd Annual Conference, San Francisco, 2016.

12 Harrison MR, Keller RL, Hawgood SB, Kitterman JA, Sandberg PL, Farmer DL, Lee H, Filly RA, Farrell JA, Albanese CT: A randomized trial of fetal endoscopic tracheal occlusion for severe fetal congenital diaphragmatic hernia. N Engl J Med 2003;349:1916-1924.

13 Hedrick MH, Estes JM, Sullivan KM, Bealer JF, Kitterman JA, Flake AW, Adzick NS, Har- rison MR: Plug the lung until it grows (PLUG): a new method to treat congenital diaphragmatic hernia in utero. J Pediatr Surg 1994;29: 612-617.

14 Nobuhara KK, Fauza DO, DiFiore JW, Hines MH, Fackler JC, Slavin R, Hirschl R, Wilson JM: Continuous intrapulmonary distension with perfluorocarbon accelerates neonatal (but not adult) lung growth. J Pediatr Surg 1998;33:292-298.

15 Mychaliska G, Bryner B, Dechert R, Kreutzman J, Becker M, Hirschl R: Safety and efficacy of perflubron-induced lung growth in neonates with congenital diaphragmatic hernia: results of a prospective randomized trial. J Pediatr Surg 2015;50:1083-1087.

16 Rotta AT, Gunnarsson B, Fuhrman BP, Wiryawan B, Hernan LJ, Steinhorn DM: Perfluorooctyl bromide (perflubron) attenuates oxidative injury to biological and nonbiological systems. Pediatr Crit Care Med 2003;4:233238.

17 Steinhorn DM, Leach CL, Fuhrman BP, Holm BA: Partial liquid ventilation enhances surfactant phospholipid production. Crit Care Med 1996;24:1252-1256.

18 von der Hardt K, Schoof E, Kandler MA, Dotsch J, Rascher W: Aerosolized perfluorocarbon suppresses early pulmonary inflammatory response in a surfactant-depleted piglet model. Pediatr Res 2002;51:177-182.

19 Mrozek JD, Smith KM, Bing DR, Meyers PA, Simonton SC, Connett JE, Mammel MC: Exogenous surfactant and partial liquid ventilation: physiologic and pathologic effects. Am J Respir Crit Care Med 1997;156:1058-1065.

20 Docimo SG, Crone RK, Davies P, Reid L, Retik AB, Mandell J: Pulmonary development in the fetal lamb: morphometric study of the alveolar phase. Anat Rec 1991;229:495-498.

21 Albertine KH, Jones GP, Starcher BC, Bohnsack JF, Davis PL, Cho SC, Carlton DP, Bland $\mathrm{RD}$ : Chronic lung injury in preterm lambs. Disordered respiratory tract development. Am J Respir Crit Care Med 1999;159:945-958.

22 Ntokou A, Klein F, Dontireddy D, Becker S, Bellusci S, Richardson WD, Szibor M, Braun T, Morty RE, Seeger W, Voswinckel R, Ahl- brecht K: Characterization of the platelet-derived growth factor receptor-alpha-positive cell lineage during murine late lung development. Am J Physiol Lung Cell Mol Physiol 2015;309:L942-L958.

23 Schmidt R, Steinhilber W, Ruppert C, Daum C, Grimminger F, Seeger W, Gunther A: An ELISA technique for quantification of surfactant apoprotein (SP)-C in bronchoalveolar lavage fluid. Am J Respir Crit Care Med 2002; 165:470-474.

24 DiFiore JW, Fauza DO, Slavin R, Peters CA, Fackler JC, Wilson JM: Experimental fetal tracheal ligation reverses the structural and physiological effects of pulmonary hypoplasia in congenital diaphragmatic hernia. J Pediatr Surg 1994;29:248-256; discussion 256-247.

25 Piedboeuf B, Laberge JM, Ghitulescu G, Gamache M, Petrov P, Belanger S, Chen MF, Hashim E, Possmayer F: Deleterious effect of tracheal obstruction on type II pneumocytes in fetal sheep. Pediatr Res 1997;41:473-479.

26 O’Toole SJ, Sharma A, Karamanoukian HL, Holm B, Azizkhan RG, Glick PL: Tracheal ligation does not correct the surfactant deficiency associated with congenital diaphragmatic hernia. J Pediatr Surg 1996;31:546-550.

27 Albuquerque CA, Nijland MJ, Ross MG: Human and ovine amniotic fluid composition differences: implications for fluid dynamics. J Matern Fetal Med 1999;8:123-129.

28 Hirschl RB, Philip WF, Glick L, Greenspan J, Smith K, Thompson A, Wilson J, Adzick NS: A prospective, randomized pilot trial of perfluorocarbon-induced lung growth in newborns with congenital diaphragmatic hernia. J Pediatr Surg 2003;38:283-289; discussion 283-289.

29 Hirschl RB, Pranikoff T, Gauger P, Schreiner RJ, Dechert R, Bartlett RH: Liquid ventilation in adults, children, and full-term neonates. Lancet 1995;346:1201-1202.

30 Hirschl RB, Conrad S, Kaiser R, Zwischenberger JB, Bartlett RH, Booth F, Cardenas V: Partial liquid ventilation in adult patients with ARDS: a multicenter phase I-II trial. Adult PLV Study Group. Ann Surg 1998;228: 692-700. 